\title{
Examining the Transactional Distance Theory in a Web-Enhanced Biology Course
}

\author{
Lawrence O. Flowers, Ph.D. (Corresponding author) \\ Assistant Professor of Microbiology \\ Department of Biological Sciences \\ Fayetteville State University \\ E-mail: lflowers@uncfsu.edu
}

Erin N. White, Ph.D.

Assistant Professor of Biology

Department of Biological Sciences

Fayetteville State University

E-mail: ewhite@uncfsu.edu

James E. Raynor, Jr., Ph.D.

Associate Professor of Cellular and Molecular Biology

Department of Biological Sciences

Fayetteville State University

E-mail: jraynor@uncfsu.edu

Received: June 24, 2012

doi:10.5296/jse.v2i3.1978
Accepted: July 16, 2012 Published: August 1, 2012

URL: http://dx.doi.org/10.5296/jse.v2i3.1978

\begin{abstract}
The current article explores Moore's theory of transactional distance in a web-enhanced introductory biology course. A questionnaire containing open-ended questions that focused on components of the transactional distance theory was utilized to examine college students' perceptions of virtual laboratories in an introductory biology course. Virtual laboratories are
\end{abstract}




\section{Macrothink}

computer-based simulations designed to inculcate specific scientific concepts and experimental procedures. Virtual laboratories are effective instructional tools in both online and traditional STEM courses. Previous research has suggested that reduction of transactional distance in the online and traditional classroom may positively influence retention rates and student learning outcomes. The qualitative findings in this study will further inform academic intervention strategies to enhance virtual laboratory instructional approaches in science, technology, engineering, and mathematics (STEM) college courses.

Keywords: Distance education, Transactional distance, Virtual laboratory, Instructional strategies, STEM 


\section{Introduction}

According to Class Differences: Online Education in the United States, several million students enrolled in at least one online course in the last few years (Allen \& Seaman, 2010), which was nearly an increase of 1 million students from the previous year. Improving student access to higher education is cited as the top reason for offering more online courses and programs. Further, increasing the rate of degree completion and the appeal of online instruction to non-traditional students are some of the other explanations regarding the growth of online instruction. To prepare for the projected increases in university and student participation in computer-mediated distance education courses, it is critical that researchers explore the advantages and disadvantages of online distance education versus traditional instruction. Moreover, with the increase in online distance education, it is clear that more research is needed to determine the extent to which this method of instruction is an effective modality and whether or not students are better able to grasp course content, as well as apply it.

Opponents to distance education initiatives cite the reduction of traditional (e.g., face-to-face) communication between instructor and students as a major criticism to web-based instruction (Arbaugh, 2000; Kruger, 2000). Another problem facing online instructors is the issue of student retention. Several studies have documented the importance of addressing course completion rates and implementing specific pedagogical practices to ensure that students are fully engaged throughout the semester (Boston, Ice, \& Gibson, 2011; Nichols, 2010). Based on a few empirical studies and unpublished qualitative data from ongoing studies at a small 4-year college in the southeastern region of the United States it is clear that retention in online courses is greatly affected by the physical separation between student and instructor. Moreover, student success in distance education courses has shown to be negatively influenced by students who perceive a lack of instructor-facilitated interaction as a barrier to learning (Abrami, Bernard, Bures, Borokhovski, \& Tamim, 2011).

The transactional distance theory is a paramount concept in web-based distance education. According to Moore (1993a) transactional distance is "a psychological and communications space to be crossed, a space of potential misunderstanding between the inputs of instructor and those of the learner” (p. 22). The fundamental concepts proposed by Moore initially involved several types of interactions: learner-content, learner-learner, and learner-instructor (Moore, 1993b). A fourth interaction, learner-interface, was later developed by Hillman, Willis, \& Gunawardena, (1994) to address the technology utilized in distance education courses and how the technology affects student perceptions of the overall learning experience. Learner-interface interaction is significant because the technology employed in online distance education courses serves as the primary conduit between the instructor and the learner. The learner-interface level of interaction involves the instructor's utilization of technology but also involves the learner's understanding and use of the online technology. It is imperative that online instructors develop appropriate teaching methods (e.g., computer usage skills, software utilization skills) to enhance a student's ability to efficiently manipulate the technology employed in distance education courses (Hillman, Willis, \& Gunawardena, 1994). The examination of learner satisfaction and precise academic outcomes associated 
with the learner-interface interaction as well as other fundamental components of the transactional distance theory are active areas of educational research (Cho, 2011). In this study, the term distance refers to the tangible division between online students and instructors during the college semester.

Virtual laboratories are web-based lab exercises designed to replicate real-world learning outcomes acquired by working in a traditional laboratory. Over the last decade the literature has reported positive outcomes of employing virtual laboratory assignments to meet curriculum learning goals in both online and traditional STEM courses (Dalgarno, Bishop, Adlong, \& Bedgood, 2009; Weisman, 2010). Specifically, the use of virtual labs in an academic setting was shown to improve students' understanding of laboratory techniques and teaching the scientific method, thus reinforcing the notion that carefully designed virtual labs can mediate beneficial learner-content interaction (Maldarelli et al., 2009).

The theory of transactional distance has broad implications in distance education and can be applied to potentiate innovative instructional approaches, promote the sustainability of distance education, and drive policy development (Gokool-Ramdoo, 2008). Given the importance of the theory of transactional distance to enhance distance education initiatives, there is a surprising lack of research articles that seek to explore the use of electronic laboratories in STEM college courses and their relationship between elements of the theory of transactional distance. The purpose of the current qualitative study is to examine student perceptions of biology-based virtual laboratories in a traditional introductory biology course for non-science majors in the context of the transactional distance theory.

\section{Methodology}

\section{Participants}

The research study was conducted at a public, four year university, located in the southeastern part of the United States. Qualitative data were collected from a purposeful sample consisting of 18 students. Student participants were comprised of three sophomores, nine juniors, and six seniors who were majoring in Business Administration, Criminal Justice, Education, Geography, History, Psychology, and Sociology.

\section{Procedure}

In order to assess the theory of transactional distance and its significance on the utilization of virtual laboratories in a STEM undergraduate course, a paper-based survey designed to address the central research questions was employed. Following Institution Review Board (IRB) approval, data collection procedures were conducted in a web-enhanced biology course for non-science majors. Web-enhanced courses are on-campus traditional courses that contain mandatory internet-based assignments (Goldberg, 2005). The survey instrument was designed based on the general types of interaction defined by Moore (1993b) and Hillman, Willis, \& Gunawardena (1994).

The survey was administered after college students completed five virtual labs that were designed to investigate the scientific method, enzyme function, cellular reproduction, 
pathology, and Mendelian genetics. Online virtual labs consisted of on-screen procedures, electronic biology exercises, post laboratory questions, and data presentation tools (e.g., data table, graph). Four open-ended research questions were used in the study: a) To what extent, if any, did your participation (e.g., completion/interaction) with the virtual laboratory increase or decrease your interaction with your professor?, b) To what extent, if any, did your participation (e.g., completion/interaction) with the virtual laboratory increase or decrease your understanding or knowledge of the biology concepts discussed in the lecture?, c) To what extent, if any, did your participation (e.g., completion/interaction) with the virtual laboratory increase or decrease your interaction with other students in the class?, d) To what extent, if any, did your participation

(e.g., completion/interaction) with the virtual laboratory increase or decrease your ability to use educational technology (e.g., Blackboard, computer simulations, e-mail)? Following data analysis, selected representative quotes were used to identify common themes. An external reviewer examined the qualitative results to determine the validity of the data. Respondents also provided information about their gender, major, and number of STEM online courses taken.

\section{Results}

Using qualitative methods previously described (Ryan \& Bernard, 2003) investigators identified the most significant student quotes that focused on elements of Moore's theory of transactional distance and the utilization of virtual laboratories in an introductory biology course. A summary of respondent quotes are shown in Table 1.

\section{Learner-Instructor Interactions}

When posed with a question regarding whether the level of interaction with the professor increased or decreased, most respondents believed that participation with virtual laboratories either decreased professor interaction or did not increase or decrease the interaction with the professor during the semester. One student noted, "Doing the virtual laboratories decreases the interaction with the professor when compared to classroom laboratories." Another student declared, "There was no real interaction with my professor regarding the VL." Similarly, a student noted, "The virtual lab didn't decrease or increase my interaction with the professor." While the majority of students reported a decrease in professor interaction, a small percentage of students reported an increase in instructor interaction. One student stated, "The virtual lab did increase the interaction with the professor." Learner-instructor interaction during the completion of all assignments is a very important concept and strategies to increase this type of interaction should be continually explored.

\section{Learner-Content Interactions}

Most of the questionnaire respondents indicated that participation with the virtual laboratories improved their understanding of biological concepts. One advantage of virtual labs is that students are able to rapidly repeat experiments under different conditions which may aid in long-term comprehension of salient course material.

One student wrote, "The virtual lab increased my understanding of science and biology." 
Likewise, another student noted, "The virtual lab helps my understanding of the concepts." According to the qualitative data there were also students who were quite surprised as to the level of their conceptual learning gains as a result of completing virtual laboratory assignments. One respondent pointed out, "The virtual labs has increased my knowledge more than I thought it would." Similarly, another student declared, "My knowledge of the biology concepts actually did increase.” Additional research questions aimed at identifying specific areas of improved biological comprehension would be significant and could lead to substantial improvements in virtual labs.

\section{Learner-Learner Interactions}

Increasing peer-peer interactions is of paramount importance to STEM instructors. Instructors are keenly aware of the enormous benefits to enhancing learner-learner interaction in terms of achieving student learning outcomes. The results of the study demonstrate that the majority of respondents believe that participation with the virtual labs decreased learner-learner interaction. One respondent shared, "It greatly decreases your interaction with other students." One student stated, "The virtual lab did not increase my participation with other students." Another student noted, "The lab neither decreased or increased interaction with other students in class." A small percentage of the questionnaire participants indicated, "It increased my interaction because I found that I talked to classmates more.” The results were somewhat expected based on the virtual lab instructions. The creation of lab groups consisting of two or more students working together to address specific research questions would improve student interactions.

\section{Learner-Interface Interactions}

Enhancing students' understanding of technology utilization skills will positively affect student performance in Internet-based courses. Both traditional and online instructors must assess their students' basic computer skills in order to assign appropriate online assignments that meet those skills. In regards to student-technology interactions, students articulated mostly positive responses after completing the virtual labs. Study participants stated, "The virtual lab increased my ability to use Blackboard.", "It really improved my ability to use educational technology.", "My participation with the virtual lab increased my ability to use educational technology.", and "The virtual laboratory increased my ability to use certain technology." The results suggest that in addition to gaining a better understanding of biological concepts that virtual laboratory use may also contribute to the enhancement of technology utilization skills. While the results reported here are positive, the open-ended question employed in this study does not allow the elucidation of the specific technology skills that were enhanced or learned.

Table 1. Summary of Student Qualitative Questionnaire Responses

Learner-Instructor Interactions

"Doing the virtual laboratories decreases the interaction with the professor when compared to 
classroom laboratories.”

"There was no real interaction with my professor regarding the VL."

“The virtual lab didn't decrease or increase my interaction with the professor."

"The virtual lab did increase the interaction with the professor."

\section{Learner-Content Interactions}

"The virtual lab increased my understanding of science and biology."

"The virtual lab helps my understanding of the concepts."

"The virtual labs has increased my knowledge more than I thought it would."

"My knowledge of the biology concepts actually did increase."

\section{Learner-Learner Interactions}

"It greatly decreases your interaction with other students."

"The virtual lab did not increase my participation with other students.”

"The lab neither decreased or increased interaction with other students in class."

"It increased my interaction because I found that I talked to classmates more.”

\section{Learner-Interface Interactions}

“The virtual lab increased my ability to use Blackboard."

"It really improved my ability to use educational technology."

"My participation with the virtual lab increased my ability to use educational technology."

"The virtual laboratory increased my ability to use certain technology."

\section{Discussion}

The current qualitative study reported herein seeks to investigate the relationship between elements of Moore's theory of transactional distance (1993a) and STEM-based virtual lab utilization in a web-enhanced general biology college course. Questionnaires were administered to gather data on student perceptions of virtual laboratories. The theory of transactional distance includes four major tenets: learner-instructor interactions, learner-learner interactions, learner-content interactions, and learner-interface interactions. Consistent with previous research, the authors agree that it is essential for traditional and online instructors to carefully consider educational research literature-derived approaches in their course development and implementation plan that includes careful attention to the theory of transactional distance. McLaren (2010) noted in a quantitative study that specific transactional instructor-student approaches can have positive effects on student satisfaction in the online environment.

The results of the current study suggest that virtual laboratories may have positive impacts (learner-content, learner-interface) as well as negative impacts (learner-learner, learner-instructor) on students' educational experiences. Results of the study also provide helpful data that can be used to improve virtual laboratory assignments. For example, students who reported an increase in professor interaction using virtual labs (Table 1) may 
also provide insights into deficiencies into virtual laboratory assignments. Responses could suggest that virtual laboratory instructions and submission procedures were inadequate or confusing which promoted an increase in students' questions and interaction with the professor. Providing additional instructions as well as a thorough review of completion and submission procedures of the web-based laboratory may be beneficial to students. Specifically, instructors can develop methods to target learner-learner and learner-instructor interactions.

Development and implementation of sustainable techniques to address transactional distance in the virtual classroom is essential. Although a variety of influential empirical studies have reported important findings impacting the success of online distance education courses, enhanced interaction between instructor and learner has emerged as a common thread (Mosser, 2010; Varre, Keane, Irvin, 2011). While there are many studies to support the argument that overall online student learning outcomes are similar to students enrolled in traditional face-to-face courses (Campbell, Floyd, \& Sheridan, 2002; Jaggars \& Bailey, 2010; Kirtman, 2009), there exists a critical need to further conduct empirical research studies that may lead to the development of innovative online pedagogical strategies designed to reduce transactional distance and enhance student learning in technology-supported distance education courses (Phipps \& Merisotis 1999; Schulte, 2010).

When teaching virtual laboratories, it is essential that professors recognize the importance of instructor-learner interactions and how these interactions influence student engagement and learning. In web-enhanced courses instructors can mitigate negative learner-instructor transactions by providing clear, concise assignment guidelines and establishing opportunities for questions. Moreover, by creating a classroom atmosphere that promotes virtual lab-based inquiries before, during, and after the assignment students are more prone to seek assistance from the professor and thereby strengthen learner-instructor interactions. Data from a multidisciplinary research study demonstrated that the use of software programs such as Elluminate Live! can facilitate synchronous communication and potentiate beneficial interaction among instructors and students enrolled in an online course (McBrien, Jones, \& Cheng, 2009). The design of both instructor-centered approaches and student-centered approaches to enhance communication between student peers and the instructor are critical and provide the basis for meaningful learning (Northrup, 2001). The elucidation of student learning styles during the first week of the course through the use of the Online Learning Styles Inventory (Liu, Shih, \& Yeh, 2010) will facilitate the design of effective learner-centered online pedagogical strategies to reduce transactional distance. An additional pedagogical strategy is the use of rubrics to ensure adherence to learner-instructor interactions, learner-learner interactions, learner-content interactions, and learner-interface interactions.

\section{Future Research}

This study relied on a theoretical framework, the theory of transactional distance, developed by Moore (1993b) and Hillman, Willis, \& Gunawardena (1994) and sought to determine the efficacy of virtual laboratory interventions to generate quality electronic learning 
environments. While the current study will significantly add to the literature base in the area of distance education several limitations to the study exist. A major limitation to this study is the sample size. Future studies should involve the inclusion of several STEM courses to increase the sample size. Future studies should also examine web-enhanced courses, hybrid courses, and fully online STEM courses to enhance the generalizability of the data. Another limitation to the study is that it only relies on specific qualitative methods (e.g., qualitative paper survey). Potentially, employing face-to-face student interviews and quantitative surveys will yield more informative results. Moreover, it is quite possible that the use of different types of web-based virtual labs may produce different results. Studies exploring a comparison of different virtual labs may give educational researchers new insights into new educational technologies.

Recommendations for future research include both qualitative and quantitative research studies to better understand instructors' and university administration perceptions of the transactional distance theory as it relates to developing and implementing sustainable online courses and degree programs. Furthermore, future studies should be constructed to address the following questions about online laboratories: a) What type of support do students seek or need in virtual laboratories in STEM courses to help them persist and learn?, b) What aspect of virtual laboratories do students find particularly helpful?, and c) What recommendations do students have for improving student engagement in virtual laboratories? Also, additional empirical studies exploring student perceptions of non-virtual laboratory pedagogical interventions in relation to one or more components of the theory of transactional distance will inform stakeholders such as distance education program directors, university administration, and online faculty.

\section{Acknowledgements}

This work was supported by a grant funded by the National Science Foundation (HRD-0811728).

\section{References}

Abrami, P., Bernard, R., Bures, E., Borokhovski, E., \& Tamim, R. (2011). Interaction in Distance Education and Online Learning: Using Evidence and Theory to Improve Practice. Journal of Computing in Higher Education, 23(2-3), 82-103. http://dx.doi.org/10.1007/s12528-011-9043-x

Allen, I. E., \& Seaman, J. (2010). Class differences: Online education in the United States, 2010. Newburyport, MA: Sloan.

Arbaugh, J. (2000). Virtual classroom characteristics and student satisfaction with internet-based MBA courses. Journal of Management Education, 24, 32-54. http://dx.doi.org/10.1177/105256290002400104

Boston, W., Ice, P., \& Gibson, A. (2011). Comprehensive Assessment of Student Retention in Online Learning Environments. OJDLA, 14(1). Retrieved from http://www.westga.edu/ distance/ojdla/spring141/boston_ice_gibson141.htm. 
Campbell, M., Floyd, J., \& Sheridan, J. (2002). Assessment of Student Performance and Attitudes for Courses Taught Online Versus Onsite. The Journal of Applied Business Research, 18(2), 45-51.

Cho, T. (2011). The Impact of Types of Interaction on Student Satisfaction in Online Courses. International Journal on E-Learning, 10(2), 109-125.

Dalgarno, B., Bishop, A., Adlong, W., \& Bedgood, D. (2009). Effectiveness of a Virtual Laboratory as a Preparatory Resource for Distance Education Chemistry Students. Computers \& Education, 53(3), 853-865. http://dx.doi.org/10.1016/j.compedu.2009.05.005

Gokool-Ramdoo, S. (2008). Beyond the Theoretical Impasse: Extending the Applications of Transactional Distance Theory. International Review of Research in Open and Distance Learning, 9(3), 1-17.

Goldberg, A. (2005). Exploring Instructional Design Issues with Web-Enhanced Courses: What Do Faculty Need in Order to Present Materials On-Line and What Should They Consider When Doing So? Journal of Interactive Online Learning, 4(1), 40-51.

Hillman, D. C., Willis, D. J., \& Gunawardena, C. N. (1994). Learner-interface interaction in distance education: An extension of contemporary models and strategies for practitioners. The American Journal of Distance Education, 8(2), 30-42. http://dx.doi.org/10.1080/08923649409526853

Jaggars, S., \& Bailey, T. (2010). Effectiveness of Fully Online Courses for College Students: Response to a Department of Education Meta-Analysis. New York, NY: Community College Research Center, Columbia University. Retrieved from the ERIC Document Reproduction Service (ED512274).

Kirtman, L. (2009). Online versus In-Class Courses: An Examination of Differences in Learning Outcomes. Issues in Teacher Education, 18(2), 103-116.

Kruger, K. (2000). Using information technology to create communities of learners. In B. Jacoby (Ed.), Involving commuter students in learning, New Directions for Higher Education, (pp. 59-70). San Francisco: Jossey-Bass.

Liu, Y., Shih, Y., \& Yeh, R. (2010). The Development of Online Learning Styles Inventory: An Exploratory Study. International Journal of Cyber Society and Education, 3(2), 99-116.

Maldarelli, G. A., Hartmann, E., Cummings, P. J., Horner, R. D., Obom, K. M., Shingles, R., \& Pearlman, R. S. (2009). Virtual Lab Demonstrations Improve Students’ Mastery of Basic Biology Laboratory Techniques. Journal of Microbiology \& Biology Education, 10, 51-56.

McBrien, J., Jones, P., \& Cheng, R. (2009). Virtual Spaces: Employing a Synchronous Online Classroom to Facilitate Student Engagement in Online Learning. International Review of Research in Open and Distance Learning, 10(3), 1-17.

Mclaren, A. (2010). The Effects of Instructor-Learner Interactions on Learner Satisfaction in Online Masters Courses. Wayne State University Dissertations. Paper 105. 


\section{Macrothink}

Journal of Studies in Education

ISSN 2162-6952

2012, Vol. 2, No. 3

Moore, M. (1993a). Theory of transactional distance. In D. Keegan (Ed.), Theoretical principles of distance education. London: Routledge.

Moore, M. (1993b). Three types of interaction. In K. Harry, M. Hohn, \& D. Keegan (Ed.), Distance education: New perspectives, (pp. 12-24). London: Routledge.

Mosser, B. (2010). The Impact of Interpersonal Interaction on Academic Engagement and Achievement in a College Success Strategies Course with a Blended Learning Instructional Model. (Doctoral dissertation). The Ohio State University Digital Dissertations.

Nichols, M. (2010). Student Perceptions of Support Services and the Influence of Targeted Interventions on Retention in Distance Education. Distance Education, 31(1), 93-113. http://dx.doi.org/10.1080/01587911003725048

Northrup, P. (2001). A framework for designing interactivity into Web-based instruction. Educational Technology, 41(2), 31-39.

Phipps, R., \& Merisotis, J. (1999). What's the difference? A review of contemporary research on the effectiveness of distance learning in higher education. Washington, DC: The Institute for Higher Education Policy.

Ryan, G., \& Bernard, H. (2003). Techniques to Identify Themes. Field Methods, 15(1), 85-109. http://dx.doi.org/10.1177/1525822X02239569

Schulte, M. (2010). Faculty Perceptions of Technology Distance Education Transactions: Qualitative Outcomes to Inform Teaching Practices. The Journal of Educators Online, 7. Retrieved from http://www.thejeo.com/Archives/Volume7Number2/Schultepaper.pdf.

Varre, C., Keane, J., \& Irvin, M. (2011). Enhancing Online Distance Education in Small Rural US Schools: A Hybrid, Learner-Centred Model. Journal of Asynchronous Learning Networks, 15(4), 35-46.

Weisman, D. (2010). Incorporating a Collaborative Web-Based Virtual Laboratory in an Undergraduate Bioinformatics Course. Biochemistry and Molecular Biology Education, 38(1), 4-9. http://dx.doi.org/10.1002/bmb.20368 